Eixo Temático: Biologia Aplicada

\title{
ET-09-004 \\ MUSGOS PLEUROCÁRPICOS DE UM REMANESCENTE DE MATA ATLÂNTICA DO COMPLEXO VEGETACIONAL UNEB/EBDA, ALAGOINHAS, BAHIA, BRASIL
}

Maise Souza Vieira ${ }^{1}$, Milena Evangelista dos Santos ${ }^{1}$, Itajilanda do Nascimento Santana ${ }^{1}$ Gracineide Selma Santos de Almeida ${ }^{2}$

${ }^{1}$ Estudante de Licenciatura em Ciências Biológicas da Universidade do Estado da Bahia, Campus II.

${ }^{2}$ Professora de Ciências Biológicas do Departamento de Ciências Exatas e da Terra - DCET da Universidade do Estado da Bahia, Campus II.

http://dx.doi.org/10.21472/congrebio2016.et-09-004

\section{RESUMO}

O presente estudo trata-se da brioflora de musgos pleurocárpicos realizado em um remanescente de Mata Atlântica do Complexo Vegetacional UNEB/EBDA localizado no município de Alagoinhas, Bahia. O presente trabalho foi desenvolvido com o intuito de contribuir para o reconhecimento da brioflora de Remanescentes de Mata Atlântica, bem como fomentar os estudos de musgos pleurocárpicos para o Estado. Foram coletadas 28 amostras perfazendo um total de nove espécies, distribuídas em oito gêneros e seis famílias. A família mais abundante em número de espécies foi Sematophyllaceae e as espécies mais representativas dentre todas as famílias foram Sematophyllum subpinnatum (Brid.) E. Britton seguido de Sematophyllum subsimplex (Hedw.) Mitt e Isopterygium tenerum (Sw.) Mitt. (PICIN/UNEB).

Palavras-chave: Pleurocarpia; Alagoinhas; Musgos.

\section{INTRODUÇÃO}

O conceito de pleurocarpia é definido pelos musgos os quais um ou mais periquécios são desenvolvidos na lateral do ramo principal, ou, ainda, no ápice dos ramos laterais (LA FARGE, 1996). Segundo Costa et al. (2010), os musgos pleurocápicos apresentam muitas vezes caulídios rastejantes e seus gametófitos costumam ser bastante ramificados, formando extensos tapetes naturais nas florestas e nos diversos substratos e, por conseqüência, desencadeia diversos benefícios ecológicos, a exemplo o combate à erosão do solo, bem como retenção de água da chuva e portanto auxilia no balanço hídrico da floresta.

As publicações que tratam de musgos pleurocárpicos são escassas para o Estado da Bahia, sendo atualmente a principal referência para estes estudos Vilas Bôas-Bastos \& Bastos (2008). Frequentemente na literatura são encontradas definições equivocadas acerca do termo pleurocarpia, tendenciando o conceito de pleurocárpico exclusivamente ao hábito, o que torna ainda mais urgente os estudos referentes a esse grupo.

De acordo com Vilas Bôas-Bastos (2008), a realização dos estudos de briófitas que possibilitem maior abrangência das áreas de Mata Atlântica no Estado da Bahia é de grande importância para o conhecimento da composição florística, bem como da distribuição e da relação entre espécies e seu microambiente. Dessa forma, o presente trabalho foi desenvolvido com o intuito de contribuir para o conhecimento da brioflora de Remanescentes de Mata Atlântica na Bahia, bem como fomentar os estudos de musgos pleurocárpicos para o Estado. 


\section{METODOLOGIA}

A área de estudo trata-se de um remanescente de Mata Atlântica do Complexo Vegetacional UNEB/EBDA localizado no município de Alagoinhas, Bahia (Figura 1). O levantamento realizou-se no período de agosto de 2015 a fevereiro de 2016, contemplando um total de 5 coletas em trilhas preestabelecidas (Figura 2). Todas as briófitas encontradas foram coletadas em todos os substratos visíveis, desde a borda ao interior da mata. Para coleta, foram utilizados canivete, pinças, sacos de papel pardo e saco plástico.

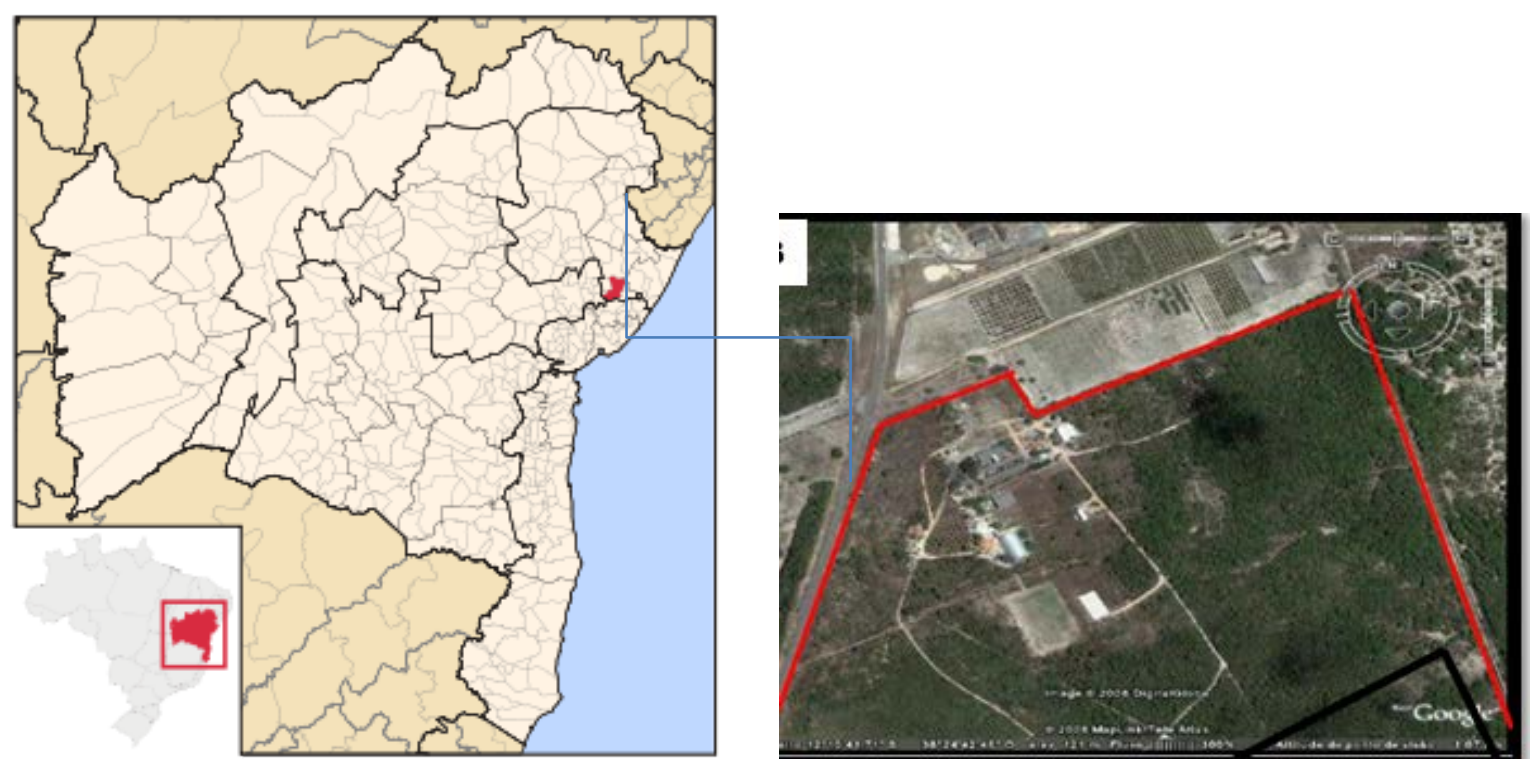

Figura 1. Localização do Complexo Vegetacional UNEB/EBDA inserido no Município de Alagoinhas, BA. Fonte: Google maps.

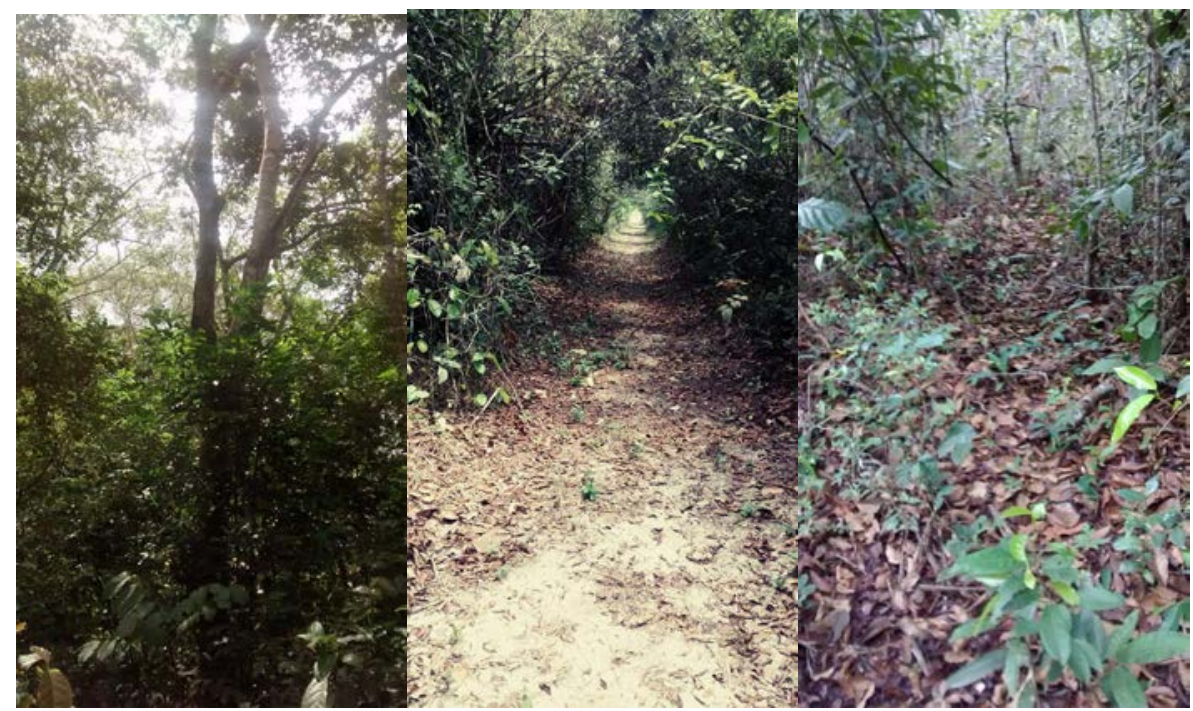

Figura 2: trilhas percorridas no período de coleta de briófitas num remanescente de Mata Atlântica do Complexo Vegetacional UNEB/EBDA. 
Após o período de coleta, o material foi desidratado em temperatura ambiente por aproximadamente 48 horas seguindo a metodologia de Yano (1984), em seguida foi triado e devidamente identificado com auxílio de lupa e microscópio através de chaves de identificação taxonômica e auxílio de especialista para confirmação das espécies. Adotou-se o sistema de classificação de Buck e Gofinnet (2004) e a distribuição geográfica foi baseada no Catálogo de Musgos Brasileiros, por Yano (2011). A diagnose das famílias foram baseadas na descrição de Buck (1998) e os domínios fitogeográficos foram consultados do banco de dados do Flora do Brasil online. A lista das espécies encontra-se organizadas por ordem alfabética. As espécies estudadas foram inseridas no Herbário da Universidade do Estado da Bahia (HUNEB), Campus II.

\section{RESULTADOS E DISCUSSÃO}

Foram coletadas 28 amostras perfazendo um total de nove espécies distribuídas em oito gêneros e seis famílias. Sendo elas: Cryphaeaceae (1spp); Fabroniaceae (1spp); Neckeraceae (1spp); Pterobryaceae (1spp); Pylaisiadelphaceae (1spp.) e Sematophyllaceae (4 spp) (Tabela 1).

A família mais abundante em número de espécies foi Sematophyllaceae e as espécies mais representativas dentre todas as famílias foram Sematophyllum subpinnatum (Brid.) E.Britton seguido de Sematophyllum subsimplex (Hedw.)Mitt e Isopterygium tenerum (Sw.) Mitt. respectivamente, o que já era de se esperar, uma vez que são espécies típicas do Bioma Mata Atlântica (embora abranjam outros domínios fitogeográficos do Brasil), evidenciando a importância do estudo da brioflora nestes locais. Além disso, já é sabido que a Floresta Atlântica vem sendo explorada intensamente todos os anos, dessa forma, o estudo de levantamento brioflorístico nestes locais é fundamental, uma vez que são consideradas pioneiras no estabelecimento de ambientes degradados e assim desempenham um importante papel por reterem a umidade do local proporcionando ambientes favoráveis ao aparecimento de espécies vegetais mais exigentes.

Foi verificado durante o estudo que os grupos briocenológicos mais evidenciados foram os corticícolos e epixílos. O primeiro pode ser justificado pela disponibilidade de espécies arbóreas presentes na área, já o segundo pode está relacionado à grande disponibilidade de fragmentos de troncos deixados na mata resultante da ação antrópica, dessa forma, o acúmulo de água e nutrientes nesses locais favorecem o estabelecimento das briófitas epíxilas.

Tabela 1. Lista de espécies de musgos pleurocárpicos encontradas no remanescente de Mata Atlântica do Complexo Vegetacional UNEB/EBDA. Os grupos briocenológicos de cada espécie estão abreviados por siglas sendo: $\mathrm{CO}$ = corticícola; $\mathrm{EP}$ = epíxila; $\mathrm{TE}$ = terrícola.

\begin{tabular}{lll}
\hline Família & Espécie & Bricenose \\
\hline Cryphaeaceae & Schoenobryum concavifolium(Griff.) Gangulee & CO \\
Fabroniaceae & Fabronia ciliaris(Brid.) Brid & CO \\
Hypnaceae & Isopterygium tenerum (Sw.) Mitt. & CO, EP, TE \\
Neckeraceae & Neckeropsis disticha (Hedw.) Kindb. & CO \\
Pterobryaceae & Henicodium geniculatum (Mitt.) W.R.Buck & EP \\
& Sematophyllum subsimplex (edw.) Mitt & CO, EP \\
Sematophyllaceae & Sematophyllum suppinnatum (Brid.) E.Britton & CO, EP \\
& Taxithelium planum(Brid.) Mitt. & EP \\
& Trichosteleum subdemissum (Besch.) A. Jaeger. & EP \\
\hline
\end{tabular}

\section{Cryphaeaceae Schimp.}

Plantas amareladas ou castanhas, ocasionalmente enegrecidas, ramificação irregularmente pinadas. Filídios imbricados quando seco, espalhando-se rapidamente quando expostos a umidade, podendo ser ovalados, ovado-lanceolados, ovado-acuminado ou levemente 
elíptico. Ápice agudo a acuminado, raramente obtuso. Costa simples, forte, percurrente à excurrente. Margens recurvadas, serruladas à crenuladas.

\section{Schoenobryum concavifolium (Griff.) Gangulee}

Gametófito atingindo até 3,5 cm long. irregularmente ramificados, coloração verdeamarela. Caulídio espesso e vermelho. Filídios ovado-lanceolados com tamanho entre 1e $2 \mathrm{~mm}$ long. Costa amarelada, percurrente, bifurcada em alguns filídios, excurrente nos filídios periqueciais. Margem inteira, células oblatas à isodiamétricas. Células da lâmina oblongas, mais estreitas próximo à costa. Células da base pouco diferenciadas. Esporófito do tipo imerso, projetando-se no ápice dos ramos secundários. Cápsula ereta, cilíndrica, peristômio simples, papilosos e claros.

Material examinado: Alagoinhas, Complexo Vegetacional UNEB- EBDA, 10 Dez. 2015, Vieira, M.S., 127.

Distribuição geográfica: AC, AL, AM, BA, CE, DF, ES, GO, MG, MS, MT, PE, PR, RJ, RO, RS, SC, SP.

Comentários: A espécie abrange os domínios fitogeográficos Amazônia, Cerrado, Mata Atlântica, Pampa e Pantanal.

\section{Fabroniaceae Schimp.}

Plantas na maioria das vezes pequenas, raramente medianas normalmente verdeescuras, formando densos tapetes. Filídios ovado, lanceolados, obtusos ou acuminados, planos ou levemente côncavos. Margens inteiras, serreadas, denteadas ou ciliadas. Costa simples delgadas a robustas, percurrente a subpercurrente. Células da laminas rombicas a longohexagonais as alares gradualmente diferenciadas quadráticas a subquadráticas.

Fabronia ciliaris (Brid.) Brid

Gametófitos verde-claros medindo entre 9 e 11mm long. Filídios entre 1 e $2 \mathrm{~mm}$ long. oblongo-lanceolados, contorcidos quando secos, costa inconspícuas, margem do filídio com uma fileira de célula lineares espaçadamente denteadas, ápice hialino. Células da lâmina romboidais, mais longas do que largas; células basais retangulares. Esporófito curto, cápsula ovóide, opérculo do tipo cônico.

Material examinado: Alagoinhas, Complexo Vegetacional UNEB- EBDA, 28 Ago. 2015, Vieira, M.S., 81.

Distribuição geográfica: AL, AM, BA, CE, DF, ES, GO, MG, MS, MT, PB, PE, PR, RJ, RS, SC, SE, SP.

Comentários: É presente nos domínios fitogeográficos Amazônia, Caatinga, Cerrado e Mata Atlântica.

\section{Hypnaceae Schimp.}

Caracterizada por serem plantas robustas; caule rastejante (pleurocárpico); ramos dispostos de forma irregular e pinados; pseudoparáfilas presentes; filídios complanados; geralmente assimétricos ovalados ou lanceolados; acuminados; costa curta ou dupla; células da lâmina dos filídios lineares, podendo variar em romboidais ou hexagonais; podem ser proradas ou papilosas.

\section{Isopterygium tenerum (Sw.) Mitt.}

Gametófitos verdes, geralmente não possuem regularidade na disposição do ramo. Filídios podem ser de ovolados a lanceolados, eretopatentes, complanados. Não possui costa; margem da lâmina inteira e serreada no ápice. Células da lâmina fusiformes, e as alares retangulares a quadráticas. Esporófitos com cápsula e seta marrom, quando maduro a cápsula é inclinada.

Material examinado: Alagoinhas, Complexo Vegetacional UNEB- EBDA, 28 Ago. 2015, Vieira, M.S., 96. 
Distribuição geográfica: AC, AL, AM, AP, BA, CE, DF, ES, GO, MA, MG, MS, MT, PA, PB, PE, PI, PR, RJ, RO, RR, RS, SC, SP, TO.

Comentários: A espécie já foi registrada nos domínios fitogeográficos Amazônia, Caatinga, Cerrado, Mata Atlântica, Pampa e Pantanal.

Neckeraceae Schimp.

Plantas monoicas ou dioicas. Filídios ovados, ovado-lanceolados, elípticos, ligulados ou espatulados. Costa simples, podendo ser conspícuas ou não, terminando abaixo do ápice. Células da lâmina estreitas e retangulares, as superiores isodiamétricas oblongo, ovais ou romboidais. Limbídios intramarginais ocasionalmente presents, parafilos presentes ou ausentes.

Neckeropsis disticha (Hedw.) Kindb.

Gametófitos extensos, ramificação irregular. Filídios fortemente complanados e ondulados quando secos; ápice truncado e fracamente serreado. Células da lâmina oblongas, as da margem mais longas, células do ápice menores e arredondadas, as da base pouco diferenciadas; costa única, não bifurcada, subpercurrente, alcançando até 20 células abaixo do ápice; filídios periqueciais não muito diferenciado. Esporófito emergente, rementas presentes ao redor do esporófito; cápsula cilíndrica; opérculo rostroso; peristômio papiloso; cílios presentes.

Material examinado: Alagoinhas, Complexo Vegetacional UNEB- EBDA, 02 Dez. 2015, Vieira, M.S., 112.

Distribuição geográfica: AC, AM (Bonfim, Rio Juruá; Rio Juruá, Marari), AP, BA, ES, GO, MG, MT, PA, PE, PR, RJ, RR, RS, SC (Tubarão perto de Conconhaz), SP (Estação Biológica de Mogi Guaçu).

Comentários: Abrange os domínios fitogeográficos Amazônia, Cerrado, Mata Atlântica e Pantanal.

\section{Pterobryaceae Kindb.}

Plantas na maioria das vezes medianas a robustas. Gametófitos eretos ou pendentes, filídios frequentemente côncavos, margens serreadas à lisas, planas a incurvadas, raramente recurvas. Costa simples, percurrente ou subpercurrente. Células lineares flexuosas, lisas as vezes prolulosas. Células alares diferenciadas podendo ser coloridas ou hialinas.

\section{Henicodium geniculatum (Mitt.) W.R.Buck}

Gametófitos variando entre 1 e 1,5 cm long. simples, verdes-claro, caulídio alaranjado. Filídios variando entre 1,5 e $2 \mathrm{~mm}$ long., inteiros, lanceolados; ápice agudo; margem plana e não diferenciadas. Células da lâmina lineares e papilosas (uma a duas papilas por célula) costados, costa única e subpercurente, células da base redondas a subquadráticas e bastante numerosas, ocupando de quatro a cinco fileiras verticais na base. Esporófito não foi encontrado no material examinado, entretanto havia grande número de gemas no indivíduo.

Material examinado: Alagoinhas, Complexo Vegetacional UNEB- EBDA, 02 Dez. 2015, Vieira, M.S., 110. RJ, RO, SP.

Distribuição geográfica: AC, AL, AM, AP, BA, CE, DF, ES, GO, MT, PA, PB, PE,

Comentários: É presente nos domínios fitogeográficos Amazônia, Cerrado, Mata Atlântica e Pantanal.

\section{Sematophyllaceae Broth}

Gametófitos possuem ramificação irregular pinada a subpinada. Filídios lanceolados ou oblongos, costa ausente ou curta. Células da lâmina romboidais à lineares podendo apresentar ou não papilas, as alares fortemente diferenciadas e usualmente infladas. 


\section{Chave de identificação para as espécies de Sematophyllaceae Para o Complexo Vegetacional UNEB/EBDA Alagoinhas, Bahia, Brasil}

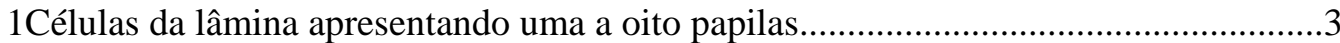

1'Células da lâmina lisas........................................................................................

2 Filídios ovado-lanceolados, células rômbicas...............Sematophyllum subpinnatum

2' Filídios lanceolados, células lineares..........................Sematophyllum subsimplex

3 Células da lâmina com seis a 8 papilas...........................................Taxithelium planum

3' Células da lâmina apenas um papila.................................Trichosteleum subdemissum

Sematophyllum subpinnatum (Brid.) E. Britton.

Gametófitos medindo entre 1 e 1,5 cm long. disposição irregular. Filídios com cerca de $1 \mathrm{~mm}$ long. ovado-lanceolados, fortemente côncavos na região madiana, ápice acuminado. Células da lâmina lisas e romboidais, as alares arredondadas, infladas e amareladas com duas células supra-alares retangulares à quadráticas. Esporófito longo, projetando-se em ramos laterais; seta lisa; cápsula pêndula e papilosa, cilíndrica; peristômio simples, opérculo longo e rostrado.

Material examinado: Alagoinhas, Complexo Vegetacional UNEB- EBDA, 28 Ago. 2015, Vieira, M.S., 99, 107, 116, 117, 118, 119, 122.

Distribuição geográfica: AC, AL, AM, AP, BA, CE, DF, ES, GO, MG, MS, MT, PA, PB, PE, PR, RJ (Jurajuba Bay), RO, RR, RS, SC, SP, TO.

Comentários: Abrange os domínios fitogeográficos Amazônia, Caatinga, Cerrado, Mata Atlântica, Pampa e Pantanal. A espécie é facilmente diferenciada das demais pelos filídios fortemente côncavos no centro pelas células romboidais da base ao ápice.

Sematophyllum subsimplex (Hedw.) Mitt.

Gametófito entre 1 e 1,5 cm long, com disposição irregular. Filídios, entre 1 e 2 mm long. dispostos da região lateral e ventral do caulídio, longo-acuminados. Células da lâmina lineares e lisas; células da base diferenciadas, sub-quadráticas e infladas; duas à três células supra-alares, ovais a quadrática, ápice dos filídios longos e não denteados. Esporófito emergido da região lateral do gametófito, seta longa, peristômio simples, cápsula horizontal, cilíndrica; opérculo obliquamente rostrado.

Material examinado: Alagoinhas, Complexo Vegetacional UNEB- EBDA, 28 de Ago. 2015, Vieira, M.S., 86, 98, 90, 91, 92, 94.

Distribuição geográfica: AC, AL, AM, AP, BA, CE, DF, ES, GO, MA, MG, MS, MT, PA, PB, PE, PI, PR, RJ, RO, RR, RS, SC, SE, SP, TO.

Comentários: A espécie é registrada pelos domínios fitogeográficos Amazônia, Cerrado, Mata Atlântica, Pantanal. Á espécie foi encontrada com frequência nos locais de coleta desde a borda ao interior da mata.

Taxithelium planum (Brid.) Mitt.

Gametófitos atingindo até 3,5 cm long., verdes-claro, ramos bipinados. Filídios com cerca de $1 \mathrm{~mm}$ long., ovado-lanceolado; ecostados; margem não diferenciada, fracamente denteada. Células da lâmina lineares pluripapilosas (6 a 8 papilas) células alares infladas, 3 a 4 células supra-alares subquadráticas. Esporófito com seta longa, cápsula cilíndrica, opérculo e caliptra não observados.

Material examinado: Alagoinhas, Complexo vegetacional UNEB-EBDA, 24 Fev. 2016, Vieira, M.S., 135.

Distribuição geográfica: AC, AL, AM, AP (Reserva Biológica do Lago Piratuba), BA, ES, GO, MA, MG, MS, MT, PA (mun. Melgaço, Flona de Caxiuanã, Estação Científi ca Ferreira Penna; Igarapé Santa Rosa; Praia do Lisboa), PB, PE, PR, RJ, RO, RR, SC, SP, TO. 
Comentários: a espécie já foi registrada para os domínios fitogeográficos Amazônia, Cerrado, Mata Atlântica e Pantanal. É diferenciada das demais pelos filídios ovalados e pelas células lineares pluripapilosas.

Trichosteleum subdemissum (Besch.) A. Jaeger.

Gametófitos verdes-pálidos, pinados, medindo até $1 \mathrm{~cm}$ long. Caulídios vermelhos. Filídios lanceolados, com cerca de $1 \mathrm{~mm}$ long; margem lisa à fracamente denteada. Células da lâmina fusiformes, unipapilosas. Células alares infladas e amareladas. Esporófito com seta longa e persistente; cápsula horizontal, cilíndrica; opérculo rostrado, peristômio simples.

Material examinado: Alagoinhas, Complexo Vegetacional UNEB-EBDA, 10 Dez. 2015, Vieira, M.S., 127.

TO.

Distribuição geográfica: AL, AM, AP, BA, DF, GO, MA, MT, PA, PI, RJ, RR, SP,

Comentários: Abrange os domínios fitogeográficos Amazônia, Cerrado e Mata Atlântica. A espécie é facilmente diferenciada pelas células unipapilosas.

\section{CONCLUSÕES}

Foram encontradas de 9 espécies distribuídas em 8 gêneros e 6 famílias;

A família mais representativa foi Sematophyllaceae com 4 espécies;

As espécies de maior ocorrência na área foram Sematophyllum subpinnatum (Brid.) E.Britton seguido de Sematophyllum subsimplex (Hedw.)Mitt e Isopterygium tenerum (Sw.) Mitt.;

Os grupos briocenológicos mais representativos foram corticícola e terrícola;

O estudo contribuiu para ampliação do número de espécies de briófitas do Herbário da Universidade do Estado da Bahia (HUNEB), Campus II.

\section{AGRADECIMENTOS}

Ao Programa Institucional de Iniciação Científica da Uneb (PICIN) pela concessão da bolsa. Ao Prof ${ }^{\circ}$ Dr. Cid Bastos e a Prof ${ }^{a}$ Dr Silvana Vilas-Bôas Bastos pela coorientação e confirmação das espécies.

\section{REFERÊNCIAS}

BUCK, W. R. Pleurocarpous mosses of the West Indies. Memoirs of The New York Botanical Garden, v. 82, p. 1-400, 1988.

BUCK, W. R.; GOFFINET, B. Morphology and classification of mosses. In: SHAW, A. J.; GOFFINET, B. (Eds). Bryophyte biology. London: Cambridge Univertsity Press, 2000.

CAMARA, P. E. A. S. Lista de espécies da flora do Brasil. Rio de Janeiro: Jardim Botânico. Disponivel em: <http://floradobrasil.jbrj.gov.br/jabot/floradobrasil/FB96988>. Acesso em: 28 abr. 2016.

COSTA, D. P.; ALMEIDA, J. S. S.; DIAS, N. S.; GRADSTEIN, S. R.; CHURCHILL, S. P. Manual de Briologia. Rio de Janeiro: Interciência, 2010.

LA-FARGE ENGLAND, C. Growth form, branching pattern and perichaetial position in mosses: cladocarpy and pleurocarpy redefined. The Bryologist, v. 99, n. 2, p. 170-186, 1996. 
VILAS BÔAS-BASTOS, S. B.; BASTOS, C. J. P. Musgos pleurocárpicos dos fragmentos de Mata Atlântica da Reserva Ecológica da Michelin, Mde Igrapiúna, BA. Feira de Santana: Universidade Estadual de Feira de Santana, 2008. (Dissertação de mestrado).

YANO, O. Técnicas de coleta, preservação e herborização de material botânico. In: 3, Briófitas. São Paulo: Instituto de Botânica, 1984. p. 27-30.

YANO, O. Catálogo de musgos brasileiros: literatura original, basiônimo, localidade-tipo e distribuição geográfica. São Paulo: Instituto de Botânica, 2011. 